\title{
Operational Characteristics of Diesel Engine Run by Ester of Sunflower Oil and Compare with Diesel Fuel Operation
}

\author{
Murugu Mohan Kumar Kandasamy \& Mohanraj Thangavelu \\ School of Mechanical Engineering, SASTRA University \\ Thanjavur 613402, Tamilnadu, India \\ E-mail: kmohan2001@rediffmail.com \\ Rajamohan Ganesan \\ School of Engineering and Science, Curtin University Technology \\ Sarawak Campus 98009, Miri, Malaysia
}

\begin{abstract}
A single cylinder direct injection diesel engine was first run with diesel fuel and then with Ester of sunflower oil. The operational characteristics of the engine run with both the fuel have been compared and the results obtained are shown in this paper. From the results obtained, it is understood that the thermal efficiency is slightly less and the specific fuel consumption is slightly higher with Ester of sunflower oil when compared with Diesel. This is due to the lower calorific value of the Ester of sunflower oil. All other parameters are also clearly discussed in this paper and finally it is concluded that the Ester of sunflower oil can be used as alternative fuel in the Diesel engine without any engine modifications.
\end{abstract}

Keywords: Diesel engine, Sunflower oil, Bio diesel, Operational characteristics and Engine performance

\section{Introduction}

The world is presently confronted with the twin crisis of fossil fuel depletion and environmental degradation. Indiscriminate extraction and lavish consumption of fossil fuels have led to reduction in underground-based carbon resources. The search for an alternative fuel, which promises a harmonious correlation with sustainable development, energy conservation management, efficiency and environmental preservation, has become highly pronounced in the present context.

Diesel fuel play an important role in transport sector and their demand is constantly increasing. Due to stringent environmental regulations, the refiners need to practice increased degree of refining to produce clean diesel fuels having lesser quantities of aromatics. This results in lowering of lubricity of diesel fuels leading to malfunctioning of fuel pumps, wear of nozzles and injector parts. The lubricity of diesel fuels can be improved by the use of additives or blending fatty acid methyl/ethyl esters (ASAE, 1996). Ester of sunflower oil is obtained by chemically modifying the neat vegetable oil, a process known as transesterification. In this process ethanol or methanol is reacted with neat vegetable oil in the presence of a catalyst to produce fatty acid esters and glycerol. This process changes the properties of the vegetable oil in to a diesel like fuel (Chang, 1997).

In the modern and fast moving world, petroleum based fuels have become important for a country's development. Products derived from crude oil continue to be the major and critical sources of energy for fuelling vehicles all over the world. However, petroleum reserves are limited and are non renewable. At the current and projected rates of consumption of crude, it is estimated that these reserves will be badly depleted in due course and it may become impossible to meet requirements. Oil availability from sources within India increased from 0.25 million tones in 1947 to about 34.56 million tones in 1989-90. This met $66 \%$ of the total demand in 1989-90. The demand for petroleum products in 1990-91 was estimated as 58.87 million tones and it was approximately 100 million tones in 2000. It is expected to reach 175 million tones in 2006-2007. Diesel is mainly consumed in the transport, industrial and agricultural sectors. The cost of transportation affects the economics of all other consumables that reach common people in a developing country like India. A country's development is strongly linked to availability of fuels for transportation and power generation.

Thus, India faces the major challenge of meeting the high demand of oil to meet the growing energy needs. It is therefore, important to have a long-term plan for development of alternative energy sources in a balanced manner by making optimal use of available land and manpower resources. It is important to explore the feasibility of substitution 
of diesel with an alternative fuel, which can be produced with in the country on a massive scale for commercial utilization. Vegetable oils are considered as good alternatives to diesel as their properties are close to diesel (Duke, 1982).

Vegetable oils are renewable in nature and can be directly used as fuels in diesel engines. However, their high viscosity and poor volatility lead to reduced thermal efficiency and increased hydrocarbon, carbon monoxide and smoke emissions (Barsic, 1981; Ali, 1995 and St.Joseph, 1982). Transesterification is one of the methods by which viscosity could be drastically reduced and the fuel could be adopted for use in diesel engine. The transesterification process involves reacting vegetable oils with alcohols such as methanol or ethanol in the presence of a catalyst (usually sodium hydroxide) at about $70^{\circ} \mathrm{C}$ to give the ester and the by product, glycerin (Korbitz, 1995). This esterified vegetable oil is popularly known as Bio-diesel and that is commercially available in the developed countries due to its distinct advantage over the conventional diesel. In our work, Sunflower oil has been converted into Bio diesel by the Transesterification method and the viscosity has been reduced to 4.8 centistokes from 21.4 centistokes. The Free fatty acids (FFA) present in the sun flower oil have got the greater influence in the process of converting it into the Bio diesel. This has been observed during the time of producing the Bio diesel in the laboratory level and that has been clearly explained in this paper (Van, 2004).

\section{Experimental Investigation and Test}

The engine is coupled with an eddy current dynamometer. Ester of Sunflower oil was injected in to the engine through the existing conventional injection system. However, two separate fuel tanks were used, one for diesel fuel and other for Ester of Sunflower oil. Both the fuels were injected at the room temperature only. A fuel changing arrangement was provided to change one fuel mode to another fuel. Since the test rig is a computerized engine test rig, all the observations were carried out by the respective sensors, i.e., the engine speed was measured by the crank angle encoder, the cylinder pressure and fuel injection pressure were measured by the piezo electric sensors. The signals that were obtained from various sensors are fed to the engine indicator for storing the data and interfacing with computer.

\section{Specification of the Engine}

$\begin{array}{lll}\text { Make a Model } & : & \text { COMET } \\ \text { No of Cylinder } & : & \text { One } \\ \text { Orientation } & : & \text { Vertical } \\ \text { Cycle } & : & 4 \text { Strokes } \\ \text { Ignition System } & : & \text { Compression Ignition } \\ \text { Bore and stroke } & : & 80 \mathrm{~mm} \times 110 \mathrm{~mm} \\ \text { Arrangement of valves } & : & \text { Overhead } \\ \text { Rated power } & : & 3.5 \mathrm{~kW} @ 1500 \mathrm{rpm} \\ \text { Cooling Medium } & : & \text { Water cooled } \\ \text { Combustion Chamber } & : & \text { Open Chamber (Direct Injection) } \\ \text { Compression ratio } & : & 18: 1 \\ \text { Displacement volume } & : & 553 \mathrm{cc}\end{array}$

\section{Engine Performance Characteristics}

\subsection{Thermal Efficiency}

The Thermal efficiency of the engine run by Ester of sunflower oil has been compared with Diesel fuel operation and it is shown in the figure 1.It is observed that the thermal efficiencies are close to each other. But however there is a slight decrease in the thermal efficiency of the Ester of sunflower oil. This is probably due to high density of Ester of sunflower oil $(0.88 \mathrm{~g} / \mathrm{cc})$ than Diesel $(0.86 \mathrm{~g} / \mathrm{cc})$ and that affects mixture formation of the fuel thus leads slow combustion. The maximum thermal efficiency of the ester of sunflower oil 31.86, where as in the case of Diesel it is $34.5 \%$.

However there is no drop in the maximum power with the Ester of sunflower oil.

\subsection{Specific Fuel Consumption}

The specific fuel consumption of Ester of sunflower oil and Diesel fuel are compared at various load is shown in figure 2. The Ester of sunflower oil has maintained similar trend as that of Diesel in the entire load range. However the SFC in the case of Ester of sunflower oil is higher as compared to Diesel. This is because of the lower calorific value of Ester of sunflower oil and that has led to more discharge of fuel for the same displacement of the plunger in the fuel injection pump. Therefore there is an increase in the SFC. At full load, the SFC of Ester of sunflower oil is $0.29(\mathrm{~kg} / \mathrm{kW}-\mathrm{hr})$ and 
for Diesel, it is $0.25(\mathrm{~kg} / \mathrm{kW}-\mathrm{hr})$.

\subsection{Exhaust Gas Temperature}

The figure 3 shows that there is no much variation in the Exhaust Gas Temperature when compare Ester of sunflower oil with Diesel fuel. The maximum temperature of exhaust gas at maximum load is $371.09 \mathrm{~K}$ for Ester of sunflower oil and $361.33 \mathrm{~K}$ for Diesel. This is because of less heating value of Ester of sunflower oil, i.e., the less heating value leads to less dissipation of heat for the same quantity of fuel burnt when compare to the Diesel fuel.

\subsection{Volumetric Efficiency}

The actual volume of air which is inducted for the combustion of Ester of sunflower oil is less with respect to stochiometric $\mathrm{A} / \mathrm{F}$ ratio of 38:1 but in the case of Diesel it is 16:1 and therefore the volumetric efficiency of the engine is decreased when Ester of sunflower oil is used as fuel and it is shown in figure 4 at different load.

\section{Engine Combustion Characteristics}

\subsection{Delay Period}

The figure 5 shows the delay period curves at different load. The delay period is the time lapse (in terms of ${ }^{\circ} \mathrm{CA}$ ) between the start of injection and the start of combustion. It is lower for Ester of sunflower oil when compare with diesel fuel. In general, the delay period in the case of C.I. engine depends on various parameters. Among all the characteristic of fuel, degrees of atomization are considered as the important factors. The decrease in fuel viscosity leads to better atomization and small sizes of fuel droplets. The smaller size of droplet requires less time for the start of combustion and hence the delay period is decreased. In our case, the viscosity of the Ester of sunflower oil is 4.8Cst. Hence atomization is slightly more and that leads to minimizing the time for start of combustion and hence there is a decrease in the delay period for Ester of sunflower oil.

\subsection{Peak Pressure}

The peak pressure depends on the amount of fuel taking part in the uncontrolled combustion phase, which is governed by the delay period and spray envelope of the injected fuel. There is a little difference between the Peak Pressure of the Ester of sunflower oil and the Diesel. In the case of Ester of sunflower oil, the delay period is less, the fuel taking part in the uncontrolled combustion phase is less and hence the Peak Pressure is slightly lesser than the diesel fuel for all the load operation is shown in figure 6.

\subsection{Rate of Pressure Rise}

The Rate of pressure rise is concerned, it is generally higher for Diesel fuel and it is probably due to the domination effects of the premixed phase of combustion and for Ester of sunflower oil it is slightly lower than Diesel fuel. This is shown in the figure 7.

\subsection{Mean Gas Temperature}

The figure 8 shows the mean gas temperature is more for ester of sunflower oil and less for diesel fuel. This is because of effective burning of ester of oil in the engine. Effective burning is made possible by the very small droplets in sizes when compare.

\section{Conclusions}

The comparison of result shows very clearly that the performance and the combustion characteristics of C.I engine using Ester of sun flower oil as a fuel are almost matching with the diesel mode of operation. This justifies that the attempt made to use Ester of sun flower oil as a fuel in the C.I engine is very effective and can be used as an alternative fuel without modifying the engine. However due to the lower calorific value of the Ester of sun flower oil, it is found that the thermal efficiency of the engine is found to be slightly lesser and the specific fuel consumption is higher with Ester of sunflower oil when compared to Diesel fuel.

\section{References}

Ali.Y., Hanna.H.A., and Leviticus.L.I. (1995). Emission and Power Characteristics of Diesel Engine on Methyl Soyate and Diesel Fuel Blends, Bio Resource Technology, Vol 52, PP 185-195.

ASAE,"EP552. (1996). Reporting Fuel Properties when Testing Diesel Engines with Alternative Fuels Derived From Biological Materials.

Barsic. N.J., and Humke.A.L.(1981). Performance and Emission Characteristics of a Naturally Aspirated Diesel with Vegetable Oil Fuels, SAE Paper 810262.

Chang.D.Y.N., and Van Gerpen.J.H. (1997). Fuel Properties and Engine Performance for Biodiesel Prepared from Modified Feed Stocks, SAE Paper 971684.

Duke.J., and Bagboy.M.O. (1982). Comparison of Oilseed Yields a Preliminary Review, Proceedings of the 
International Conference on Plant and Vegetable Oils as Fuels, American Society of Agricultural Engineers, St. Joseph, Mich.

Korbitz.W. (1995). Status and Development of Biodiesel Production and Projects in Europe and North America, SAE Paper No. 952768, Society of Automotive Engineers, Warren Dale.

St.Joseph.M. (1982). Vegetable Oil Fuels Proceedings of the International Conference on Plant and Vegetable Oils as Fuels, American Society of Agriculture Engineers.

Van.G.J., Shanks.B., and Pruszko.R.D., Clements, and Knothe.G. (2004). Biodiesl Production Technology”, Report from Iowa State University for the National Renewable Energy Laboratory, NREL/SR-510-36244.

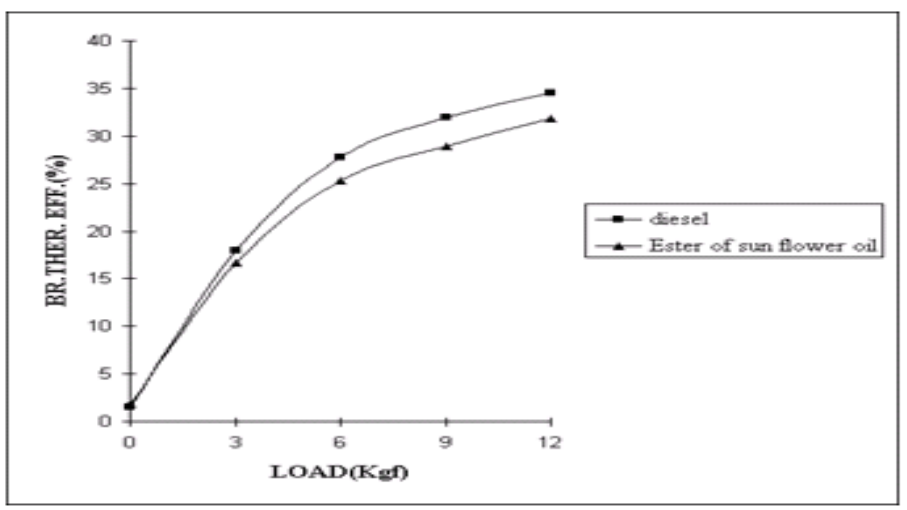

Figure 1. Load versus Brake thermal efficiency

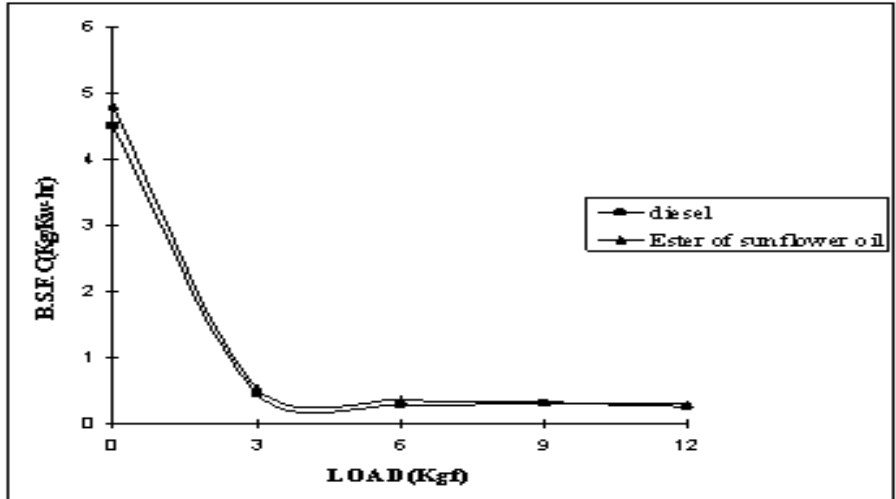

Figure 2. Load versus Brake specific fuel consumption

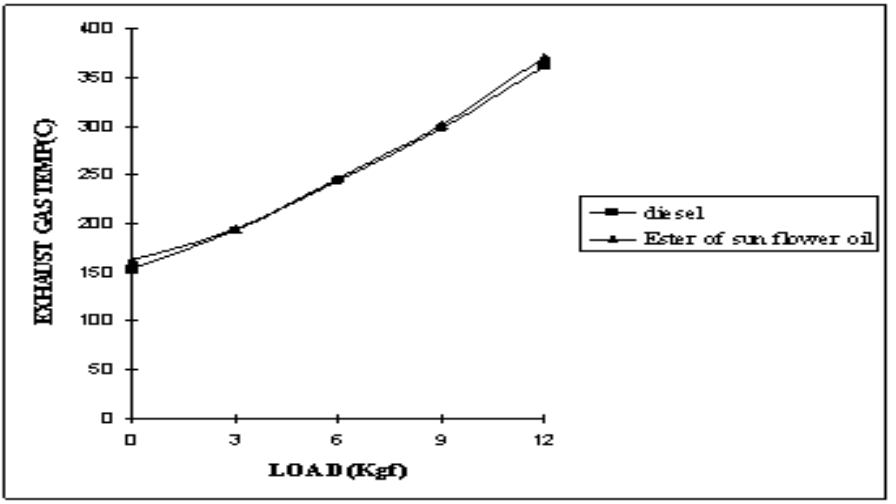

Figure 3. Load versus Exhaust gas temperature 


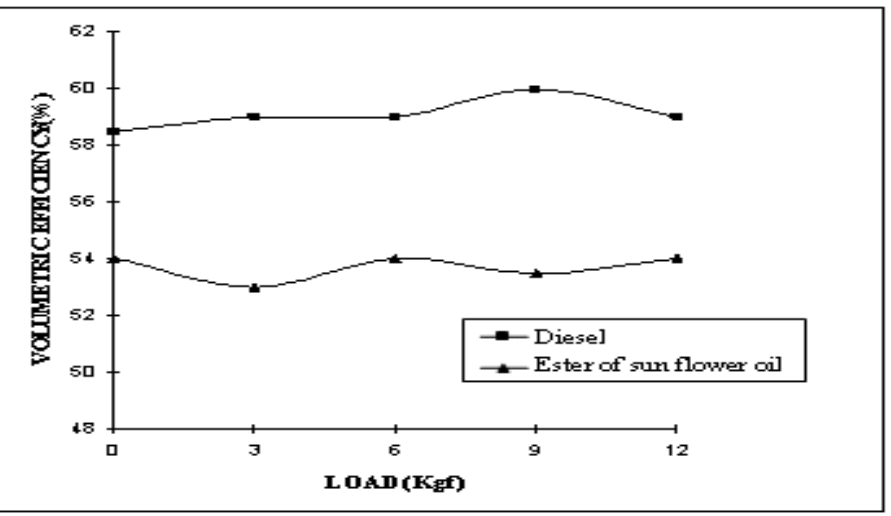

Figure 4. Load versus Volumetric efficiency

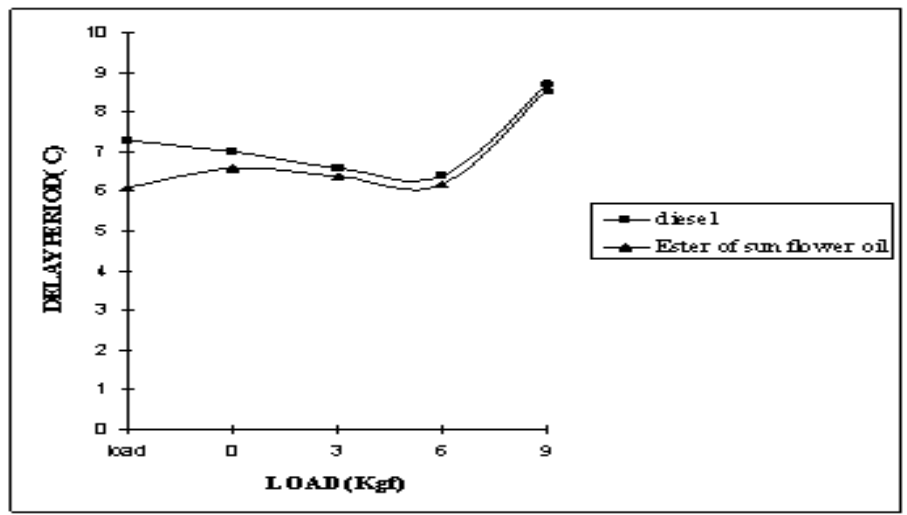

Figure 5. Load versus Delay period

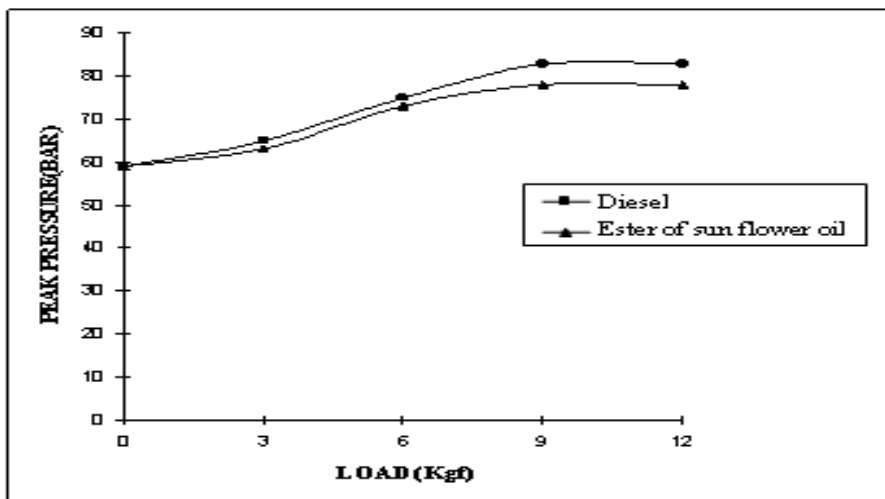

Figure 6. Load versus Peak pressure

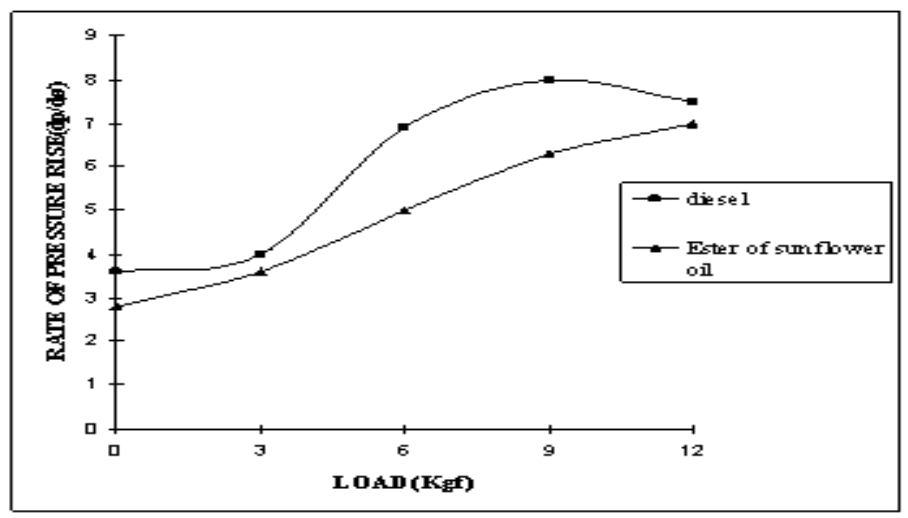

Figure 7. Load versus Rate of pressure rise 


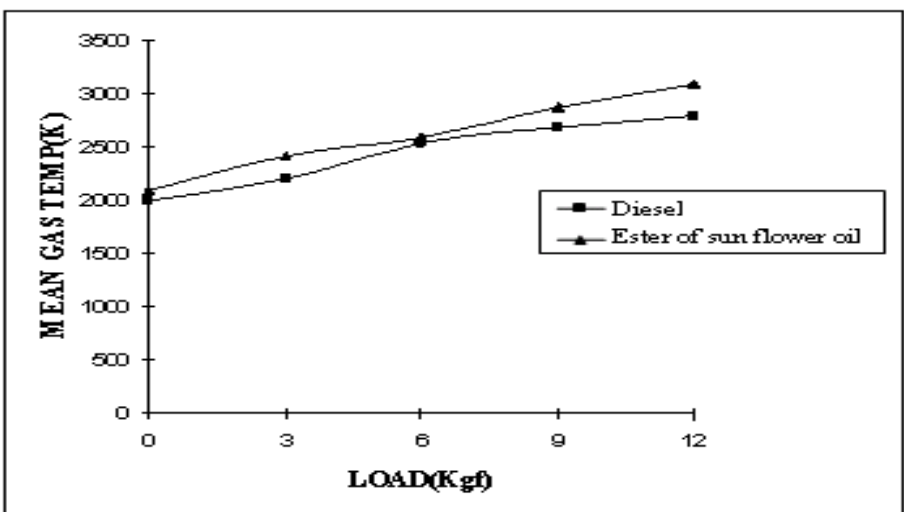

Figure 8. Load versus Mean gas temperature 